\title{
Effect of Aerobic Exercise and Vitamin D Supplementation on Expression of Apoptosis-Regulatory Genes in Lung of Rats Poisoned with Hydrogen Peroxide
}

\author{
Seyedeh Tahereh Haeri (PhD \\ candidate) \\ $\mathrm{PhD}$ student of Sports Physiology, \\ Islamic Azad University, Central \\ Tehran Branch, Tehran, Iran \\ Mohammad Ali Azarbayjani(PhD) \\ Professor of Sports Physiology, \\ Islamic Azad University, Central \\ Tehran Branch, Tehran, Iran \\ Maghsoud Peeri(PhD) \\ Professor of Sports Physiology, \\ Islamic Azad University, Central \\ Tehran Branch, Tehran, Iran \\ Corresponding author: Mohammad \\ Ali Azarbayjani \\ Email: m_azarbayjani@iauctb.ac.ir \\ Tel: +98-9123172908 \\ Address: College of Physical \\ Education and Sports Sciences, Islamic \\ Azad University, Central Tehran \\ Branch, Tehran, Iran \\ Received: 13 Dec 2018 \\ Revised: 02 Jan 2019 \\ Accepted: 20 Jan 2019

\section{cc) (i) (8)} \\ This work is licensed under a Creative \\ Commons Attribution 4.0 License.
}

\section{ABSTRACT}

Background and Objectives: Apoptosis is essential for the survival and normal functioning of multicellular organisms, yet any interruption in this process could be detrimental. Increased production of reactive oxygen species and oxidative stress are key factors affecting apoptosis. Our objective was to determine the impact of exercise with and without vitamin I supplementation on expression of FLIP, Fas, and caspase 8 in lung of rats poisoned with $\mathrm{H}_{2} \mathrm{O}_{2}$.

Methods: Forty-eight adult male rats were randomly divided into six groups: (C), (H), (HI), (HE), (HDE) and dimethyl sulfoxide. Groups H, HE, HI and HDE received $\mathrm{Lmmol} / \mathrm{Kg}$ intraperitoneal injection of $\mathrm{H}_{2} \mathrm{O}_{2}$. HE and HDE groups ran on treadmill for eight weeks. Expression of FLIP, Fas and caspase 8 was measured in lung tissues using RT-qPCR. Statistical analysis of data was carried out using SPSS 22 at significance level of 0.05 .

Results: Vitamin II supplementation caused a significant decrease in expression of Fas $(\mathrm{P}=0.014)$ and caspase $8(\mathrm{P}=0.016)$ compared to the control group. However, it significantly overexpressed FLIP in the lung tissues compared to the control group $(\mathrm{P}=0.005)$. Exercise with and without vitamin I supplementation had no significant effect on the expression of the apoptosis regulatory genes.

Conclusion: 0ur results show that VI exerts protective effects on lung tissue by regulating apoptotic factors. Aerobic exercise alone and combined with VD has no significant effect on the apoptotic factors. These results indicate that VI supplementation can reduce lung injury under oxidative stress conditions.

KEYWORDS: Apoptosis, Vitamin I, Exercise.

This paper should be cited as: Haeri st, Azarbayjani MA, Peeri M [Effect of Aerobic Exercise and Vitamin D Supplementation on Expression of Apoptosis-Regulatory Genes in Lung of Rats Poisoned with Hydrogen Peroxide]. mljgoums. 2019; 13(4):17-22 


\section{INTRODUCTION}

Respiratory diseases are one of the most common causes of human death worldwide (1). Approximately 1.2 million people are diagnosed with lung cancer every year (2). It has been proposed that reactive oxygen species (ROS) may be involved in lung injury (3). ROS can induce apoptosis by activating cellular apoptotic pathways or causing damage to cellular components such as DNA, mitochondria and lysosomes (4).

Vitamin D (VD) can reduce risk of cancer by regulating cell proliferation and differentiation and inhibiting angiogenesis (5). Endurance exercise at moderate intensity reduces oxidative stress and muscle damage, while intensive endurance exercise have adverse effects on the body's antioxidant defense system by increasing the production of free radicals (6). VD also exerts pro-differentiating and anti-metastatic effects by regulating transcription of more than 60 genes (5). VD protects epithelial cells against $\mathrm{H}_{2} \mathrm{O}_{2}$-induced oxidative stress by inhibiting apoptosis and production of superoxide anion (7). VD can induce apoptosis in cancer cells through p53dependent and independent pathways (1).

In recent years, several studies have investigated the effects of different types of training on apoptosis. Unlike intestine exercise, performing moderate and sustained exercise can decrease apoptosis in different tissues (8-10). Oxygen free radicals can damage cellular structures and DNA, which may lead to apoptosis (11). Regular physical activity strengthens the antioxidant defense system and protects the body against free radicals-induced damage. It is well-established that regular physical activity has an important role in prevention or control of some lung diseases (12). In this study, we determine effects of aerobic exercise with and without VD supplementation on expression of apoptosis regulatory genes in rats poisoned with $\mathrm{H}_{2} \mathrm{O}_{2}$.

\section{MATERIALS AND METHODS}

The study was carried out on 48 adult male Wistar rats aged 8-10 weeks (weighting $220 \pm 20 \mathrm{~g}$ ). The rats were kept at $22{ }^{\circ} \mathrm{C}$ on a 12:12 h light/dark cycle. All experiments on the animals were approved by the ethics committee of the Kerman University of Medical Sciences (ethical approval code: IR.KMU.REC.1396.1562). The rats were randomly and equally divided into six groups: control group (C), poisoned with hydrogen peroxide $(\mathrm{H})$, hydrogen peroxide and $\mathrm{VD}$ (HD), hydrogen peroxide and aerobic exercise (HE), hydrogen peroxide, VD and aerobic exercise (HDE) and dimethyl sulfoxide (DMSO) with saline. Animals were weighed every two weeks and their food consumption was monitored on a daily basis. Rats in the $\mathrm{HD}, \mathrm{HE}, \mathrm{H}$ and HDE groups received intraperitoneal injection of $0.1 \mathrm{mg} / \mathrm{Kg} \mathrm{H}_{2} \mathrm{O}_{2}$ (Merck, Germany) three times a week. Rats in the HD and HDE group received daily intraperitoneal injection of $0.5 \mu \mathrm{g} / \mathrm{Kg}$ body weight VD (300,000 IU, Dithrecol, Caspian Tamin Co., Iran) for eight weeks (13). Normal saline was used to dilute VD and DMSO was used to dissolve VD in saline.

Subjects in the HE and HDE group ran on a rat running wheel for eight weeks. Table 1 shows the duration and speed of exercise over the eight-week intervention (14).

Rats began running at speed of $15 \mathrm{~m} / \mathrm{min}$ for 2 minutes. The speed of running wheels was increased by $1.8 \mathrm{~m} / \mathrm{min}$ every 2 minutes until the rats were unable to run. $\mathrm{VO}_{2} \max$ values were calculated based on the correlation between speed of running wheel and rats' $\mathrm{VO}_{2} \max$ (15). The $\mathrm{VO}_{2} \max$ values were determined at baseline, at the end of the fourth week and at the end of eighth week (16).

Twenty four hours after the last training session and following 12 hours of fasting, the rats were sacrificed and lungs were exposed to avoid extra production of internal ROS (17). The lung tissue was removed, immediately washed with $0.1 \%$ phosphate buffer and fixed in RNAlater solution (Ambion, L/N: 1206029, USA). The tissue samples were homogenized using a rotor stator homogenizer (Tissue Rupture, 230V, 50-60 Hz, QIAGEN, Germany) and then kept at $-55{ }^{\circ} \mathrm{C}$ for 20 minutes. Total RNA was extracted from $30 \mathrm{mg}$ of wet tissue using RNeasy Mini Kit (QIAGEN, Germany). After centrifugation for 25 to 30 minutes, the mixture was transferred to a new tube and treated with pure ethanol. After washing with buffer RW1, the mixture was directly transferred to a storage containing a special filter. After adding $30 \mu \mathrm{l}$ of water, total RNA was collected and kept in $-20{ }^{\circ} \mathrm{C}$. The extracted RNA solution was treated with DNasI enzyme. Quality of the extracted RNA was measured by reading absorbance at 
260/280 nm and electrophoresis on $1 \%$ agarose gel. For synthesis of cDNA, $5 \mu \mathrm{g}$ of each RNA sample were mixed with oligo-dT primers (Parstous Biotechnology) and reverse transcriptase according to kit manufacturer's instructions (Parstous Biotechnology). The primers were designed using the Primer 3 software For performing two-stage PCR, reverse transcription to cDNA was performed using Real-Time Quantitative Reverse Transcription PCR (RT-PCR) high capacity RNA to cDNA kit. Total RNA was converted to cDNA by adding $1000 \mathrm{ng}$ RNA $(10 \mu \mathrm{l}$ of buffer RT and $1 \mu \mathrm{l}$ of RT). All experiments were conducted in triplicate in a StepOnePlus ${ }^{\mathrm{TM}}$ Real-Time PCR System (Applied Biosystems, USA). Amplification conditions were as follows: reverse transcription at $48{ }^{\circ} \mathrm{C}$ for $15 \mathrm{~min}$, activation of ampli-Taq gold DNA polymerase at $95^{\circ} \mathrm{C}$ for
10 min, 40 cycles of denaturation at $95^{\circ} \mathrm{C}$ for $15 \mathrm{~s}$ and 0 cycles of annealing at $60^{\circ} \mathrm{C}$ for 1 min. Beta-actin and glyceraldehyde-3phosphate dehydrogenase (GAPDH) were used as the housekeeping genes. Data was analyzed according to the comparative $\mathrm{Ct}$ method $\left(2^{-\Delta \Delta \mathrm{Ct}}\right)(18)$.

PCR primers and a TaqMan probe with a dye label (FAM) was ordered from Thermo Fisher Scientific for Fas (Rn00685720_m1), FLIP (Rn01438105_m1), caspase 8 (Rn01440170_m1), beta actin (Rn00667869_m1) and GAPDH (Rn01775763_g1). Data were analyzed with SPSS 22 at significance level of 0.05. Oneway analysis of variance was performed for determining the effect of receiving $\mathrm{H}_{2} \mathrm{O}_{2}$ (1 mmol.Kg). Two-way analysis of variance was used for independent groups to determine effect of exercise and VD supplementation.

Table 1- Duration and speed of exercise over the eight-week intervention period

\begin{tabular}{ccc}
\hline Week & Speed $(\mathbf{m} /$ min) & Time $(\mathbf{m i n})$ \\
\hline 1 & $\mathbf{8}$ & $\mathbf{3 0}$ \\
2 & 12 & 30 \\
3 & 16 & 45 \\
4 & 20 & 45 \\
5 & 20 & 60 \\
6 & 20 & 60 \\
7 & 20 & 60 \\
8 & 20 & 60 \\
\hline
\end{tabular}

\section{RESULTS}

Fas expression was significantly higher in group $\mathrm{H}$ compared to group $\mathrm{C}(\mathrm{P}=0.0001)$. Exercise had no significant effect on expression of the Fas gene ( $\mathrm{P}=0.598)$, while VD supplementation significantly decreased Fas expression $(\mathrm{P}=0.205)$. Combination of exercise and VD supplementation had no significant effect on Fas expression $(\mathrm{P}=0.734$, Figure 1).
Exercise had no significant effect on expression of the FLIP gene $(\mathrm{P}=0.863)$, but VD supplementation caused a significant increase in FLIP expression $(\mathrm{P}=0.005)$. Combination of exercise and VD supplementation had no significant effect on FLIP expression $(\mathrm{P}=0.531$, Figure 2).

Figure 1- Expression of the Fas gene in different groups

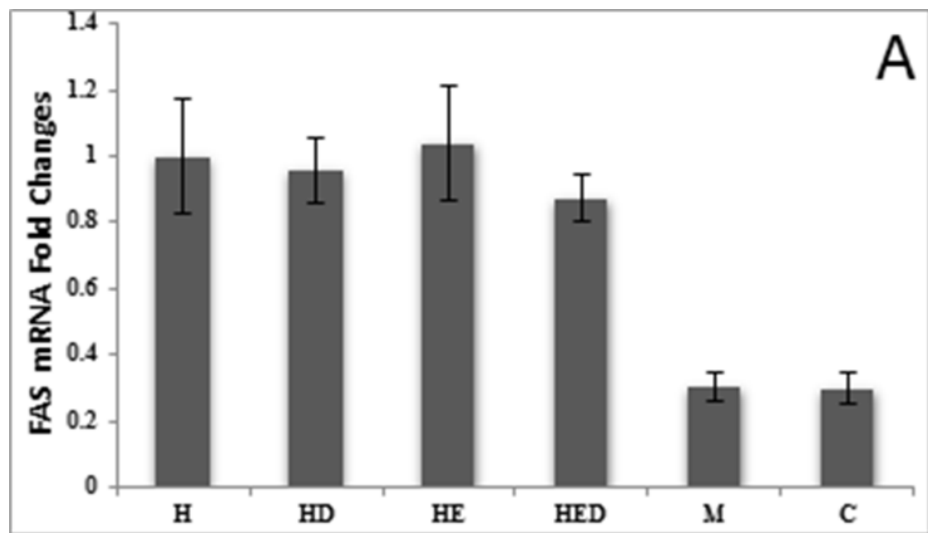




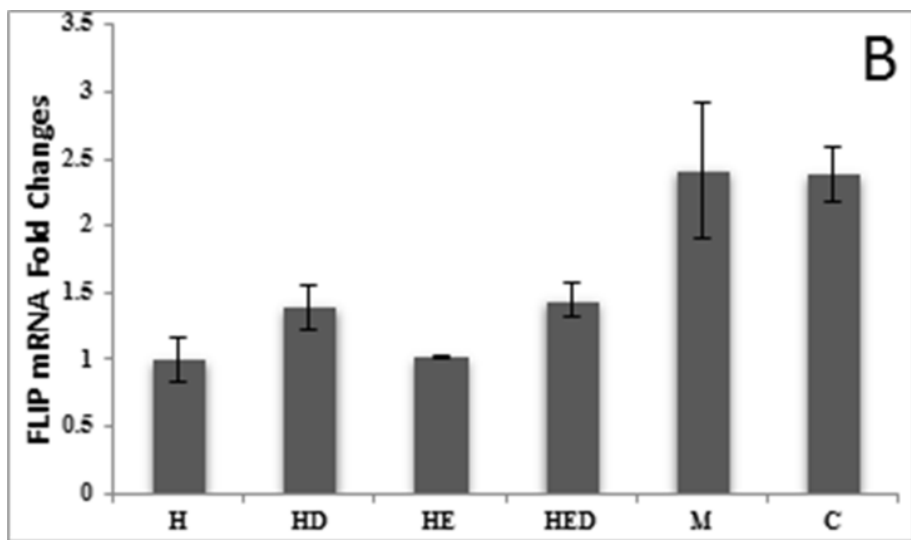

Exercise had no significant effect on caspase 8 expression $(\mathrm{P}=0.245)$, but $\mathrm{VD}$ caused a significant decrease in caspase 8 expression
$(\mathrm{P}=0.016)$. Combination of exercise and VD had no significant effect on caspase 8 expression $(\mathrm{P}=0.238$, Figure 3$)$.

Figure 3- Caspase 8 expression in different groups

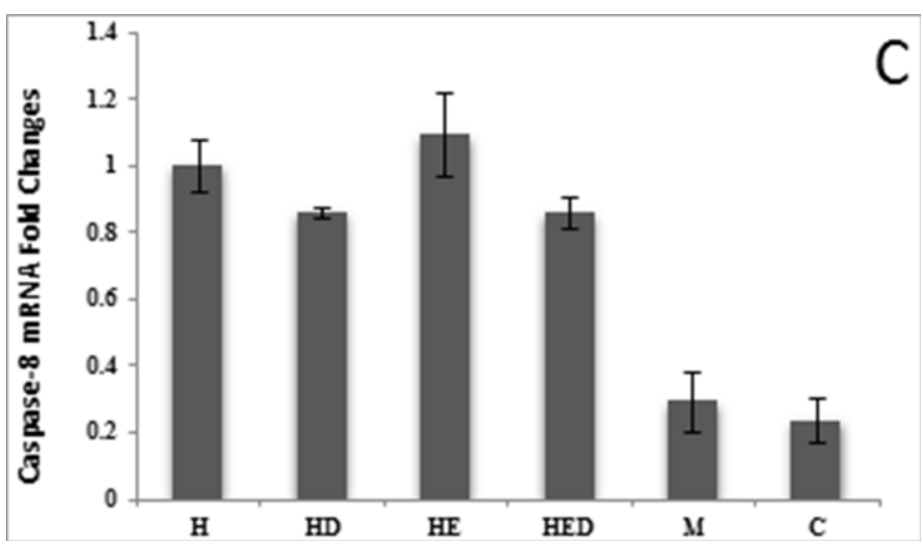

\section{DISCUSSION}

Our findings showed that eight weeks of regular aerobic exercise with or without VD supplementation had no significant effect on expression of caspase 8, Fas and FLIP in rats exposed to hydrogen peroxide. In line with our findings, Koopman et al. reported that moderate exercise caused no change in the percentage of apoptotic cells (19). Some studies demonstrated that unlike intensive exercise, moderate intensity exercise causes little or no apoptosis $(6,20)$. According to Dumont et al., Fas (CD95) system is not essential for $\mathrm{H}_{2} \mathrm{O}_{2}$-induced apoptosis (21).

Several metabolic and hormonal changes may occur during exercise which can result into cell damage or apoptosis in laboratory conditions. For instance, corticosteroids, catecholamines and cortisol can induce apoptosis in peripheral blood lymphocytes in a time-, concentration- and exercise intensitydependent manner (22). It is possible that the exercise intensity in our study was not high enough to increase level of these hormones to cause apoptosis. Numerous studies have Shown that exercise can alter calcium levels in cytosol, which is an essential intracellular signal that interferes with the apoptotic processes. In addition, increased cytosolic calcium level prior to apoptosis has been detected in some cell types (21). It is likely that the exercise in our study was not intense enough to increase cytosolic calcium level.

It has been demonstrated that aerobic exercise including running can significantly decrease FasL level $(6,23,24)$.

In a study, thirty minutes of daily pedaling on ergometer bike for 12 weeks considerably decreased soluble forms of Fas and FasL (24). There seems to be a direct relationship between concentration of apoptotic mediators and exercise intensity $(25,26)$. The lack of effect on apoptotic mediators could also be due to insufficient amount of $\mathrm{H}_{2} \mathrm{O}_{2}$ used for the induction of oxidative stress (10). VD has been identified as a strong regulator of growth, differentiation, angiogenesis and 
apoptosis (27). In our study, VD supplementation decreased Fas and caspase 8 expression and increased FLIP expression compared to the control group.

Zeng et al. reported that VD supplementation can lower the overexpressed Fas and FasL in hearts of rats with diabetic cardiomyopathy (28). Other studies also reported that calcitriol exerts anti-apoptotic effects through regulation of Bcl-2 (29, 30). Active form of VD can also inhibit FAS- and TNF $\alpha$-induced apoptosis by lowering LEX-1 transcription, which plays a role in cell survival (31).

Zhang et al. demonstrated that pretreatment with $1,25 \quad(\mathrm{OH})_{2} \mathrm{D}_{3}$ decreases apoptosis induction by TRAIL and FasL, while continuous treatment with this compound induces apoptosis in ovarian cancer cells (32). In our study, VD supplementation reduced apoptosis in pulmonary cells through decreasing proapoptotic factors Fas and caspase 8 and increasing anti-apoptotic factor FLIP. However, VD supplementation combined with

\section{REFERENCES}

1. Ferdinandy P, Schulz R. Nitric oxide, superoxide and peroxynitrite in pulmonary ischemia- reperfusion injury and preconditioning. Br J Pharmacol. 2003; 138(4): 53243.

2. Brown JC, Winters-Stone K, Lee A, Schmitz KH.Cancer, Physical Activity, and Exercise. Compr Physiol. 2012; 2(4): 2775-809. doi: 10.1002/cphy.c120005.

3. Jeroudi MO, Hartley CJ, Bolli R. pulmonary reperfusion injury role of oxygen radicals and potential therapy with antioxidants. Am J Cardiol. 1994; 73(6): 2B-7B.

4. Weitsman GE, Koren R, Zuck E, Rotem C, Liberman UA, Ravid A.Vitamin D sensitizes breast cancer cells to the action of H2O2: Mitochondria as a convergence point in the death pathway. Free Radic Biol Med. 2005; 39(2): 266-78.

5. Ali MM, Vaidya V. Vitamin D and cancer. J Cancer Res Ther. 2007; 3(4): 225-30.

6. Kruger K, Frost S, Most E, Volker K, Pallauf J, Mooren FC. Exercise affects tissue lymphocyte apoptosis via redox-sensitive and Fas-dependent signaling pathways. Am J Physiol Regul Integr Comp Physiol. 2009; 296: R1518-27. doi: 10.1152/ajpregu.90994.2008.

7. Polidoro L, Properzi G, Marampon F, Gravina GL, Festuccia C, Di Cesare E, et al. Vitamin D protects human endothelial cells from $\mathrm{H}_{2} \mathrm{O}_{2}$ oxidant injury through the Mek/Erk-Sirtl axis activation. J Cardiovasc Transl Res. 2013; 6(2): 221-31. doi: 10.1007/s12265012-9436-x.

8. Peterson JM, Bryner RW, Sindler A, Frisbee JC, Alway SE. Mitochondrial apoptotic signaling is elevatedin cardiac but not skeletal muscle in the obese Zucker rat and is reduced with aerobic exercise. $\mathrm{J}$ Appl Physiol 2008; 2008; 105(6): 1934-1943. aerobic exercise had no notable impact on Fas, caspase 8 and FLIP. This could be related to negative effects of oxidative stress and calcitriol on expression of VD receptor (33).

\section{CONCLUSION}

Our results show that VD exerts protective effects on lung tissue by regulating apoptotic factors. Aerobic exercise alone and combined with VD has no significant effect on the apoptotic factors. These results indicate that VD supplementation can reduce lung injury under oxidative stress conditions.

\section{ACKNOWLEDGEMENTS}

Our deepest gratitude goes to the faculty of physiology at Kerman University of Medical Sciences for their cooperation and support.

\section{CONFLICT OF INTEREST}

The authors declare that there is no conflict of interest regarding publication of this article.

9. McMillan EM, Graham DA, Rush JWE, Quadrilatero J. Decreased DNA fragmentation and apoptotic signaling in soleus muscle of hypertensive rats following 6 weeks of treadmill training. J Appl Physiol (1985). 2012; 113(7): 1048-57. doi: 10.1152/japplphysiol.00290.2012.

10. Quadrilatero J, Bombardier E, Norris SM, Talanian JL, Palmer MS, Logan HM, et al. Prolonged moderateintensity aerobic exercise does not alter apoptotic signaling and DNA fragmentation in human skeletal muscle. Am J Physiol Endocrinol Metab. 2010; 298(3): E534-47. doi: 10.1152/ajpendo.00678.2009.

11. Podhorska-Okolow M, Dziegiel P, Gomulkiewicz A, Kisiela D, Dolinska-Krajewska B, Jethon Z, et al. Exercise-induced apoptosis in rat kidney is mediated by both angiotensin II AT1 and AT2 receptors. Histol Histopathol. 2006; 21(5): 459-66. doi: 10.14670/HH21.459 .

12. Adams AK, Best TM. The role of antioxidants in exercise and disease prevention. Phys Sportsmed. 2002; 30(5): 37-44. doi: 10.3810/psm.2002.05.281.

13. Halder SK, Sharan C, Al-Hendy A. 1, 25dihydroxyvitamin D3 treatment shrinks uterine leiomyoma tumors in the Eker rat model. Biol Reprod. 2012; 86(4): 116. doi: 10.1095/biolreprod.111.098145.

14. Husain K, Hazelrigg SR. Oxidative injury due to chronic nitric oxide synthase inhibition in rat: effect of regular exercise on the heart. Biochim Biophys Acta. 2002; 1587(1): 75-82.

15. Nibbelink KA, Tishkoff DX, Hershey SD, Rahman A, Simpson RU. 1,25(oh)2-vitamin d3 actions on cell proliferation, size, gene expression, and receptor localization, in the hl-1 cardiac myocyte. J Steroid Biochem Mol Biol. 2007; 103(3-5): 533-7. 
16. Libonati J, Gaughan J, Hefner C, Gow A, Paolone A, Houser S. Reduced ischemia and reperfusion injury following exercise training. Med Sci Sports Exerc. 1997; 29(4): 509-16.

17. DeLuca H F, Overview of general physiologic features and functions of vitamin d. Am J Clin Nutr 80 (2004) 1689S-96S.

18. Wong ML, Medrano JF. Real-time PCR for mRNA quantitation. Biotechniques. 2005; 39(1): 75-85.

19. Koopman G, Reutelingsperger CP, Kuijten GA, Keehnen RM, Pals ST, van Oers MH. Annexin V for flow cytometric detection of phosphatidylserine expression on B cells undergoing apoptosis. Blood. 1994; 84(5): 141520.

20. Mooren FC, Bloming D, Lechtermann A, Lerch MM, Volker K. Lymphocyte apoptosis after exhaustive and moderate exercise. J Appl Physiol. 2002; 93(1):147-53.

21. Dumont A, Hehner SP, Hofmann TG, Ueffing M, Dröge W, Schmitz ML. Hydrogen peroxide-induced apoptosis is CD95-independent, requires the release of mitochondria-derived reactive oxygen species and the activation of NF-kappaB. Oncogene. 1999; 18(3): 74757.

22. Cioca DP, Watanabe N, Isobe M. Apoptosis of peripheral blood lymphocytes is induced by catecholamines. Jpn Heart J. 2000; 41(3): 385-98.

23. Pereira G, Prestes J, Tibana R, Shiguemoto G, Navalta J, Perez S. Acute resistance training affects cell surface markers for apoptosis and migration in CD4+ and CD8+ lymphocytes. Cellular Immunology. 2012; 279(2):134-9.

24. Adamopoulos S, Parissis J, Karatzas D, Kroupis C, Georgiadis M, Karavolias G, et al. Physical trainin modulates proinflammatory cytokines and the soluble Fas/soluble Fasligand system in patients with chronic heart failure. J Am Coll Cardiol. 2002; 39(4): 653-63.

25. Mooren FC, Lechtermann A, Völker K. Exerciseinduced apoptosis of lymphocytes depends on training status. Med Sci Sports Exerc. 2004, 36(9):1476-83.
26. Navalta JW, Sedlock DA, Park KS. Effect of exercise intensity on exercise induced lymphocyte apoptosis. Int $\mathrm{J}$ Sports Med. 2007; 28(6): 539-42.

27. Osborne JE, Hutchinson PE. Vitamin D and systemic cancer: is this relevant to malignant melanoma? $\mathrm{Br} \mathrm{J}$ Dermatol. 2002; 147(2):197-213.

28. Xiaoyun Zeng, Xintian Yu, Shan Xiao, Hua Yao, Jun Zhu. Effects of 1,25-dihydroxyvitamin D3 on pathological changes in rats with diabetic cardiomyopathy. Lipids in Health and Disease. 2017; 16:109. doi.org/10.1186/s12944-017-0498-2.

29. Marcinkowska E, Chrobak A, Wiedłocha A. Evading apoptosis by calcitriol-differentiated human leukemic HL-60 cells is not mediated by changes in CD95 receptor system but by increased sensitivity of these cells to insulin. Exp Cell Res. 2001; 270(1):119-27.

30. Zhang L, Lin J, Guo J, Sun W, Pan L. Effects of 1 , 25-(OH)2D3 on airway remodeling and airway epithelial cell apoptosis in a murine model of asthma. Zhonghua Yi Xue Za Zhi. 2015; 95(48): 3945-9. doi: 10.3760/cma.j.issn.0376-2491.2015.48.016.

31. Kobayashi T, Pittelkow MR, Warner GM, Squillace KA, Kumar R. Regulation of a novel immediate early response gene, IEX-1, in keratinocytes by lalpha,25dihydroxyvitamin D3. Biochem Biophys Res Commun. 1998; 251(3): 868-73

32. Zhang $\mathrm{X}$, Li $\mathrm{P}$, Bao J, Nicosia SV, Wang $\mathrm{H}$, Enkemann SA, et al. Suppression of Death Receptormediated Apoptosis by 1,25-Dihydroxyvitamin D3 Revealed by Microarray Analysis. J Biol Chem. 2005; 280(42): 35458-68.

33. Salhan D, Husain M, Subrati A, Goyal R, Singh T, Rai P, Malhotra A, Singhal PC. HIV-induced kidney cell injury: role of ROS-induced downregulated vitamin D receptor. Am J Physiol Renal Physiol. 2012; 303(4): F503-51. 